\title{
Budget Impact Analysis of Gemtuzumab Ozogamicin for the Treatment of CD33-Positive Acute Myeloid Leukemia
}

\author{
Carla Mamolo ${ }^{1} \oplus \cdot$ Verna Welch $^{2} \cdot$ Roland B. Walter $^{3,4} \cdot$ Joseph C. Cappelleri ${ }^{5} \cdot$ James Brockbank $^{6} \cdot$ Matthew Cawson $^{6}$. \\ Chris Knight $^{6} \cdot$ Michele Wilson $^{7}$
}

Accepted: 29 October 2020 / Published online: 25 November 2020

(c) The Author(s) 2020

\begin{abstract}
Background Gemtuzumab ozogamicin (GO) was approved in 2017 in the US for the treatment of adults with newly diagnosed CD33-positive (CD33+) acute myeloid leukemia (AML), and adults and pediatric patients with CD33+ relapsed/ refractory (R/R) AML.

Objective The aim of this study was to estimate the budgetary impact of introducing GO to a 1-million-member US health plan over a 5-year period.

Methods We developed models to estimate the impact of introducing GO in combination with conventional induction chemotherapy or as monotherapy for newly diagnosed AML, and as monotherapy for R/R AML. Models were built using data on drug costs and treatment-related outcomes obtained from published clinical trials and other publicly available sources. Results were reported on a per member/per year and per member/per month (PMPM) basis.

Results Base-case results of the newly diagnosed model indicated that the addition of GO in the combination setting reduced the overall budget of a 1-million-member health plan. The estimated net cost (US\$) savings ranged from $\$ 72,969$ (\$0.006 PMPM) in year 1 to $\$ 745,426$ (\$0.062 PMPM) in year 5. In the monotherapy setting, GO was associated with increased net costs ranging from $\$ 4118$ (0.0003 PMPM) in year 1 to $\$ 31,885$ (\$0.003 PMPM) in year 5. Base-case results of the R/R AML model demonstrated increased net costs that ranged from $\$ 17,326$ (\$0.001 PMPM) in year 1 to $\$ 46,163$ (\$0.004 PMPM) in year 5. Scenario analyses in all settings indicated the budget impact was not overly sensitive to the selected input assumptions, with the exception of the scenario considering only the pharmacy budget impact in the combination setting.

Conclusions The introduction of GO for newly diagnosed and R/R AML would have a minimal impact on the budget of a US health plan and could result in cost savings in the combination therapy setting for newly diagnosed AML.
\end{abstract}

Electronic supplementary material The online version of this article (https://doi.org/10.1007/s40273-020-00976-6) contains supplementary material, which is available to authorized users.

Carla Mamolo

carla.mamolo@pfizer.com

1 Patient \& Health Impact, Pfizer Inc, 445 Eastern Point Road, Groton, CT 06833, USA

2 Patient \& Health Impact, Pfizer Inc, New York, NY, USA

3 Clinical Research Division, Fred Hutchinson Cancer Research Center, Seattle, WA, USA

4 Division of Hematology, Department of Medicine, University of Washington, Seattle, WA, USA

5 Statistics, Pfizer Inc, Groton, CT, USA

6 RTI Health Solutions, Manchester, UK

7 RTI Health Solutions, Research Triangle Park, NC, USA

\section{Key Points for Decision Makers}

Gemtuzumab ozogamicin (GO) was approved in 2017 in the US for the treatment of adults with newly diagnosed CD33-positive (CD33+) acute myeloid leukemia (AML) and all patients $\geq 2$ years of age with relapsed/refractory (R/R) CD33+ AML.

Results of our budget impact analysis indicated GO for newly diagnosed CD33+ AML would have minimal effect on a US health plan budget and would result in cost savings in the combination therapy setting due to GO-associated reductions in transplant and relapse.

Results also indicated a minimal budget impact to a US health plan with the addition of GO for R/R AML. 


\section{Introduction}

In 2018, there were over 20,000 new cases of acute myeloid leukemia (AML) in the US alone [1]. AML remains difficult to treat, with estimates that over 10,000 patients will die annually in the US from this malignancy [1]. AML has a median age at diagnosis of 68 years and is most frequently diagnosed in adults aged 65-74 years [1]. Older age is associated with poorer outcomes, including lower rates of remission and survival compared with younger patients [2].

For younger adult patients (age $<60$ years), the standard induction therapy has been the ' $7+3$ ' regimen (cytarabine continuously for 7 days in combination with an anthracycline for the first 3 days); consolidation therapy may include intensive chemotherapy and/or hematopoietic stem cell transplantation (HSCT) when appropriate [2-4]. Although a majority of adults $<60$ years of age can achieve complete remission following standard induction chemotherapy, most patients will eventually relapse $[2,3,5,6]$. Older patients (age $\geq 60$ years) are less likely to achieve complete remission, and many are unable to tolerate intensive chemotherapy due to the risk of toxicity [3]. Treatment selection in older patients may take into account a number of factors, including performance status, comorbidities, and other adverse features $[2,3]$. If patients are deemed unable to tolerate intensive chemotherapy, first-line treatment has been limited to best supportive care, clinical trials with investigational drugs, low-dose cytarabine, or hypomethylating agents such as azacitidine or decitabine alone or in combination with other agents $[3,7]$. Patients with relapsed or refractory $(\mathrm{R} / \mathrm{R})$ AML have few treatment options and no agreedupon standard-of-care therapy [3]. Salvage regimens such as fludarabine, cytarabine, granulocyte colony-stimulating factor (G-CSF), and idarubicin (FLAG-IDA), mitoxantrone, etoposide, and cytarabine (MEC), or high-dose cytarabine (HiDAC) with or without mitoxantrone, idarubicin, or daunorubicin may be used $[3,6,7]$.

With conventional treatments, improvements in AML outcomes over the past few decades have been modest and have been primarily attributable to advances in supportive care and HSCT techniques [8-10]. However, the treatment landscape for AML is rapidly changing with the approval of a number of novel therapies over the past 2-3 years [11], including refinements of conventional cytotoxic chemotherapies, molecular targeted inhibitors, and immunotherapies [12-18].

Gemtuzumab ozogamicin (GO) is a CD33-directed antibody conjugated to a potent, cytotoxic calicheamicin derivative. The CD33 antigen is expressed on at least a subset of AML cells in almost all patients, and represents an important target for antibody-based AML therapy [19]. GO was reapproved by the US FDA in 2017 as monotherapy or in combination with chemotherapy for adults with newly diagnosed CD33-positive (CD33+) AML, and as monotherapy for adult and pediatric patients aged $\geq 2$ years with R/R CD33+ AML [12]. Key clinical trials leading to the approval of GO as combination therapy for newly diagnosed AML included the ALFA-0701, MRC AML15, and NCRI AML16 trials (Table 1) [20-22]. The EORTC-GIMEMA AML-19 and MyloFrance-1 trials supported the approval of GO as monotherapy for newly diagnosed and R/R AML, respectively (Table 1) [23, 24].

The economic burden of AML to commercial insurers in the US is substantial, with the greatest cost components being hospitalization during and after induction therapy and the use of allogeneic HSCT [25, 26]. Newer treatments for AML can be costly but may also add value through increased clinical benefits and lower associated medical costs, such as decreased hospitalizations and delayed need for HSCT [27]. Given the already large economic burden of AML, it is important to assess the potential impact of adding newer therapies to a health plan. In the current analysis, we evaluated the budget impact of adding GO to a 1-million-member US health plan for the treatment of patients with AML.

\section{Methods}

\subsection{Model Structure}

This analysis included models for evaluating the budget impact of introducing GO for the treatment of newly diagnosed and R/R AML to a 1-million-member US health plan over a 5-year period. The time horizon was selected based on the International Society for Pharmacoeconomics and Outcomes Research (ISPOR) best practice guidelines for budget impact analyses [28]. All indications for GO approved by the US FDA were included in the models. For newly diagnosed AML, the model estimated the incremental budget impact of introducing GO in combination with standard chemotherapy versus standard chemotherapy alone for patients eligible for intensive chemotherapy, and as monotherapy versus azacitidine or decitabine for patients ineligible for intensive chemotherapy (Fig. 1a). Although no head-to-head trials have examined single-agent GO versus azacitidine or decitabine, we nevertheless opted to include them as comparators because they are commonly used agents for patients ineligible for intensive chemotherapy. For R/R AML, the model estimated the incremental impact of introducing single-agent $\mathrm{GO}$ versus alternative regimens currently used in this setting: HiDAC, FLAG-IDA, and MEC (Fig. 1b).

Models were programmed in Microsoft Excel and Microsoft Visual Basic for Applications and conducted in accordance with the ISPOR best practice guidelines for budget 
Table 1 Key clinical trials supporting the approval of GO for AML

\begin{tabular}{|c|c|c|}
\hline Trial & Patients and treatment & Outcomes $^{\mathrm{a}}$ \\
\hline \multicolumn{3}{|c|}{ GO in combination with chemotherapy for newly diagnosed $A M L$} \\
\hline ALFA-0701 [20] & $\begin{array}{l}\text { Patients with untreated de novo AML, aged } \\
50-70 \text { years } \\
\text { GO dose: } 3 \mathrm{mg} / \mathrm{m}^{2} \text { on days } 1,4 \text {, and } 7 \text { of induc- } \\
\text { tion; day } 1 \text { of each of two consolidation courses } \\
\text { Comparator: chemotherapy alone }\end{array}$ & $\begin{array}{l}\text { GO vs. no GO arm: } \\
\text { Higher EFS (2-year rate: } 40.8 \% \text { vs. } 17.1 \% \text { ) } \\
\text { Higher OS (2-year rate: } 53.2 \% \text { vs. } 41.9 \% \text { ) } \\
\text { Higher RFS (2-year rate: } 50.3 \% \text { vs. } 22.7 \% \text { ) }\end{array}$ \\
\hline MRC AML15 [21] & $\begin{array}{l}\text { Patients with untreated AML, predominantly } \\
\text { younger }(<60 \text { years }) \\
\text { GO dose: } 3 \mathrm{mg} / \mathrm{m}^{2} \text { on day } 1 \text { of induction; day } 1 \text { of } \\
\text { consolidation } \\
\text { Comparator: chemotherapy alone }\end{array}$ & $\begin{array}{l}\text { GO vs. no GO arm: } \\
\text { Higher OS among favorable-risk patients } \\
(5 \text {-year rate: } 79 \% \text { vs. } 51 \%)^{\mathrm{b}}\end{array}$ \\
\hline NCRI AML16 [22] & $\begin{array}{l}\text { Patients with untreated AML or high-risk } \\
\text { myelodysplastic syndrome, predominantly older } \\
\text { (>60 years) } \\
\text { GO dose: } 3 \mathrm{mg} / \mathrm{m}^{2} \text { on day } 1 \text { of induction } \\
\text { Comparator: chemotherapy alone }\end{array}$ & $\begin{array}{l}\text { GO vs. no GO arm: } \\
\text { Lower relapse ( } 3 \text {-year cumulative inci- } \\
\text { dence: } 68 \% \text { vs. } 76 \%) \\
\text { Higher OS (3-year rate: } 25 \% \text { vs. } 20 \% \text { ) }\end{array}$ \\
\hline \multicolumn{3}{|c|}{ GO as monotherapy for newly diagnosed $A M L$} \\
\hline EORTC-GIMEMA AML-19 [23] & $\begin{array}{l}\text { Patients with previously untreated AML who were } \\
\text { ineligible for intensive chemotherapy } \\
\text { GO dose: } 6 \mathrm{mg} / \mathrm{m}^{2} \text { on day } 1 \text { and } 3 \mathrm{mg} / \mathrm{m}^{2} \text { on day } 8 \\
\text { of induction; thereafter, up to eight monthly } \\
\text { courses of } 2 \mathrm{mg} / \mathrm{m}^{2} \\
\text { Comparator: BSC (included blood product infu- } \\
\text { sions, antimicrobials, hydroxyurea, etc.) }\end{array}$ & $\begin{array}{l}\text { GO vs. BSC arm: } \\
\text { Higher OS (1-year rate: } 24.3 \% \text { vs. } 9.7 \% \text { ) }\end{array}$ \\
\hline \multicolumn{3}{|l|}{$G O$ as monotherapy for $R / R A M L$} \\
\hline MyloFrance-1 [24] & $\begin{array}{l}\text { Patients with AML in first relapse } \\
\text { GO dose: } 3 \mathrm{mg} / \mathrm{m}^{2} \text { on days } 1,4 \text {, and } 7 \\
\text { Comparator: none (single-arm trial) }\end{array}$ & $\begin{array}{l}\text { GO efficacy: } \\
\text { ORR (CR + CRp) rate: } 33 \% \\
\text { Median OS: } 8.4 \text { months } \\
\text { Median RFS: } 11.0 \text { months }\end{array}$ \\
\hline
\end{tabular}

$A M L$ acute myeloid leukemia, $B S C$ best supportive care, $C R$ complete remission, $C R p$ complete remission with incomplete platelet recovery, $E F S$ event-free survival, $G O$ gemtuzumab ozogamicin, $O R R$ overall response rate, $O S$ overall survival, $R F S$ relapse-free survival, $R / R$ relapsed/ refractory, $S C$ standard chemotherapy

${ }^{\text {a } D i f f e r e n c e s ~ i n ~ o u t c o m e s ~ p r e s e n t e d ~ h e r e ~ w e r e ~ s t a t i s t i c a l l y ~ s i g n i f i c a n t ~}$

${ }^{\mathrm{b}}$ With the addition of GO to induction; no benefit was observed with GO use in consolidation

impact analyses [28]. Results are reported on a per member per year and per member per month (PMPM) basis.

\subsection{Model Inputs}

\subsubsection{Newly Diagnosed Acute Myeloid Leukemia (AML)}

The modeled patient population included patients indicated for first-line treatment with GO. The number of patients eligible for treatment was estimated using the standard health plan population assumption of 1 million people and an AML incidence of $0.0042 \%$ obtained from the Surveillance, Epidemiology, and End Results (SEER) Program [1].

Population characteristics were based on the ALFA-0701 study population [20]. A total of $90 \%$ of patients with AML were assumed to be $\mathrm{CD} 33+$ and therefore eligible to receive GO. Cytogenetic risk status determined eligibility for intensive chemotherapy with GO. Patients with favorable (3.3\%) or intermediate $(66.4 \%)$ risk were considered eligible, and patients with unfavorable (21.0\%) risk were considered ineligible, for intensive chemotherapy containing GO. Patients with an unknown (9.2\%) risk status were assumed to be distributed in the same relative proportions as observed across the favorable, intermediate, and unfavorable risk categories. Mean body surface area (BSA) was assumed to be $1.83 \mathrm{~m}^{2}$ (standard deviation [SD] 0.198) and was also based on the ALFA-0701 study population.

The treatment regimen for GO in combination with standard chemotherapy consisted of one induction cycle and two consolidation cycles. The recommended dose of GO was $3 \mathrm{mg} / \mathrm{m}^{2}$ (up to $4.5 \mathrm{mg}$ ) on days 1,4 , and 7 of induction, and $3 \mathrm{mg} / \mathrm{m}^{2}$ (up to $4.5 \mathrm{mg}$ ) on day 1 of consolidation [12]. Patients requiring a second induction cycle did not receive $\mathrm{GO}$ in the second cycle. Because the standard chemotherapy regimen with or without GO is the same, only the additional cost of GO treatment is reported.

The treatment regimen for single-agent GO consisted of one induction cycle and up to eight continuation cycles. 
a. Newly diagnosed AML

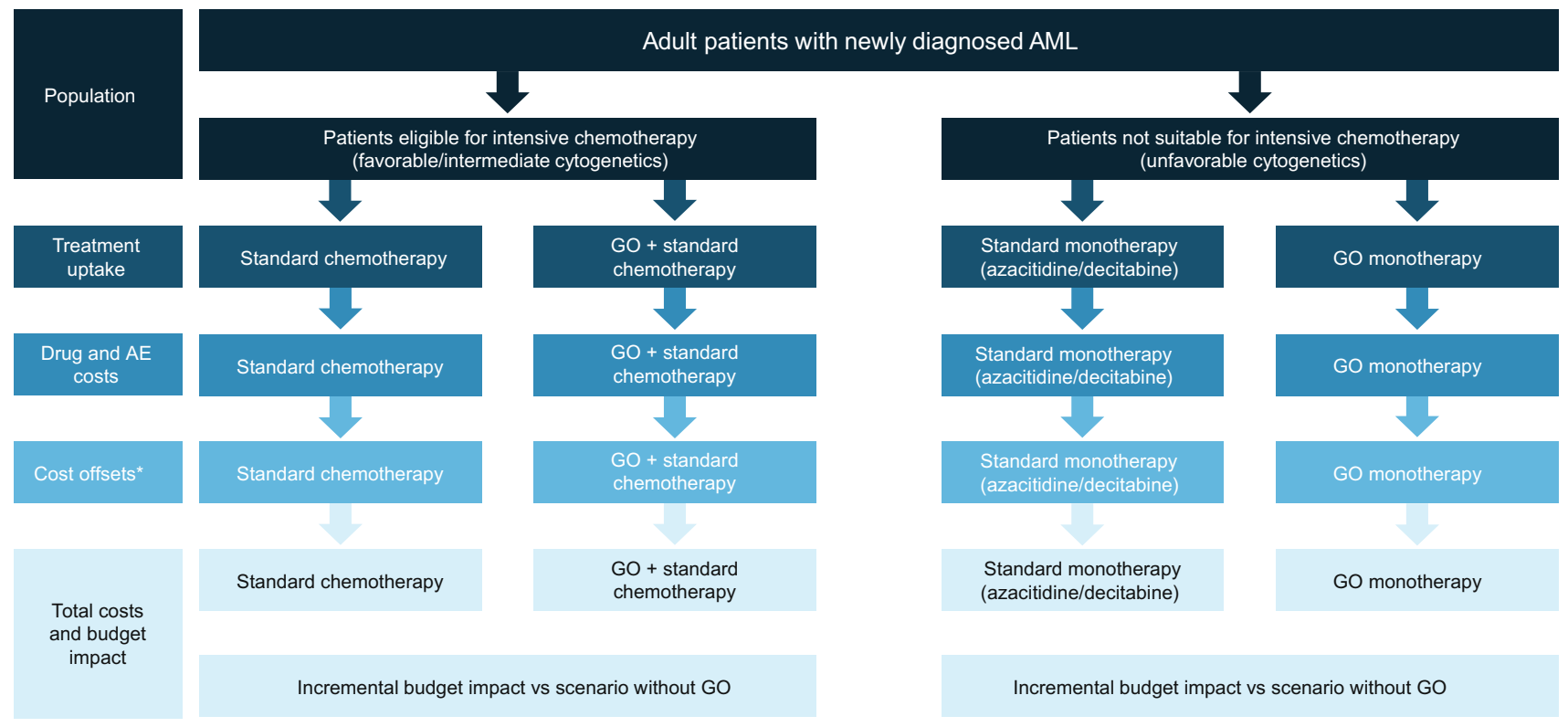

\section{b. R/R AML}

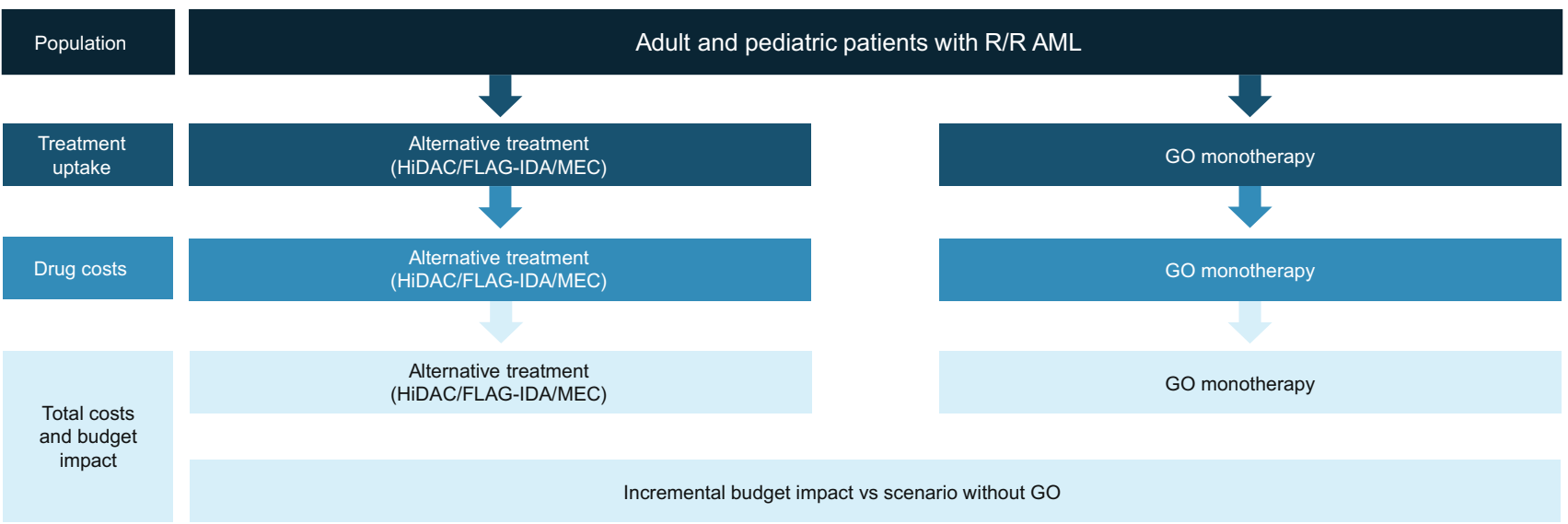

Fig. 1 Model structure for the budget impact analysis of GO for a newly diagnosed AML and $\mathbf{b} \mathrm{R} / \mathrm{R}$ AML. ${ }^{*}$ Cost offsets related to relapse, transplant, and survival. $A E$ adverse event, $A M L$ acute myeloid leukemia, FLAG-IDA fludarabine, high-dose cytarabine, granulo-

The recommended dose of GO was $6 \mathrm{mg} / \mathrm{m}^{2}$ on day 1 and $3 \mathrm{mg} / \mathrm{m}^{2}$ on day 8 of induction, and $2 \mathrm{mg} / \mathrm{m}^{2}$ on day 1 every 4 weeks during continuation. The dosing for the comparator treatments was azacitidine $75 \mathrm{mg} / \mathrm{m}^{2}$ for 7 days or decitabine $20 \mathrm{mg} / \mathrm{m}^{2}$ for 5 days. For simplicity, the model assumed $50 \%$ of patients each received azacitidine or decitabine.

Drug dosing in both treatment settings was determined using a method-of-moments analysis capturing the variation in patients' BSA around the mean and its impact on vial use (Online Resource 1) [29]. Method-of-moments is cyte colony-stimulating factor, and idarubicin, $G O$ gemtuzumab ozogamicin, $H i D A C$ high-dose cytarabine, $M E C$ mitoxantrone, etoposide, and cytarabine, $R / R$ relapsed/refractory

a recognized methodology in economic modeling to derive more accurate estimates of drug costs that use weight or BSA dosing schedules [30]. The unit prices of the treatments were sourced from Red Book 2017 [31] and were used to calculate drug acquisition costs.

The model examined different estimated uptake rates (base-case estimate in Table 2); scenario analyses reflected a $20 \%$ higher and a $20 \%$ lower treatment uptake for GO.

The cost of grade 3 and 4 adverse events (AEs) was captured in the model when the difference in incidence was 
$>2 \%$ between treatment arms. Incidence estimates were based on the ALFA-0701 trial for GO in combination with chemotherapy [20]. AEs included in the analysis were hemorrhage, liver events, skin or mucosa events, gastrointestinal events, infection, and neutropenia (Online Resource 2). Weighted costs were estimated by multiplying the probability of each AE by the unit cost for the AE, obtained from the published literature [32-34].

The model included cost offsets for GO treatment related to transplants and relapses in a combination therapy setting (Table 2). Rates of transplant and relapse for years 1-5 following treatment initiation were derived from the ALFA0701 trial, which reported outcomes for 3 years [35]. As such, we extrapolated the probabilities of events for the 4 th and 5 th years following treatment initiation based on a bestfit exponential function of the first 3 years post-treatment. We obtained the cost of relapse and the cost of hematopoietic stem cell transplant $(\$ 197,209$ and $\$ 263,744$, respectively) from previously published costing studies of AML patients [36, 37]. Finally, although GO did not achieve a statistically significant increase in overall survival in the ALFA-0701 trial [35], we conservatively assumed the numerical increase in survival for patients receiving GO treatment from the ALFA-0701 trial and applied a 'survival cost' of $\$ 155,436$ [38] for each subsequent year to those additional patients surviving due to treatment with GO. We also present a scenario analysis assuming no difference in overall survival, as well as a scenario assuming no cost offsets or AEs.

Because the monotherapy population trial did not include a comparator arm, and due to a lack of robust clinical trial data for treatment alternatives in monotherapy AML at the time of analysis, comparison with alternative treatments was not feasible in the monotherapy setting. As such, the model assumed clinical outcomes (relapses, transplants, AEs) were similar across treatments. Thus, we present only the drug costs for the monotherapy setting as there was no assumed incremental impact of GO on the costs of AEs and treatment outcomes.

\subsubsection{Relapsed/Refractory AML}

The modeled patient population included adult and pediatric patients indicated for GO for the treatment of AML in first relapse and was consistent with the population described in the final efficacy and safety report by Taksin et al. [24]. The number of patients eligible for treatment was estimated using the standard health plan population assumption of 1 million people (adult population $77.2 \%$; pediatric population $22.8 \%$ ) and an AML incidence of $0.0042 \%$ for adults and $0.0009 \%$ for pediatric patients, obtained from the SEER Program [1]. In all, $57.1 \%$ of patients with AML were estimated to receive second-line treatment based on a prior analysis of outcomes in patients with AML [39], and 90\% of patients were assumed to be CD33+ and eligible for GO treatment

Table 2 Estimated uptake and transplant and relapse rates

\begin{tabular}{|c|c|c|c|c|c|}
\hline & Year 1 & Year 2 & Year 3 & Year 4 & Year 5 \\
\hline \multicolumn{6}{|l|}{ Uptake estimates } \\
\hline \multicolumn{6}{|l|}{ Newly diagnosed AML } \\
\hline Combination therapy & 8.0 & 29.8 & 49.9 & 54.0 & 54.0 \\
\hline Monotherapy & 2.3 & 9.4 & 16.6 & 18.0 & 18.0 \\
\hline \multicolumn{6}{|l|}{ Relapsed/refractory AML } \\
\hline Adult patients & 9.4 & 17.7 & 23.2 & 23.2 & 23.2 \\
\hline Pediatric patients & 2.7 & 8.3 & 17.2 & 21.2 & 21.2 \\
\hline $\begin{array}{l}\text { Outcomes after de novo treatment } \\
\text { initiation }^{\text {a }}\end{array}$ & First year & Second year & Third year & Fourth year & Fifth year \\
\hline \multicolumn{6}{|l|}{ Probability of relapse [35] } \\
\hline $\mathrm{GO}+$ standard chemotherapy & 38 & 24 & 2 & 1 & 0 \\
\hline Standard chemotherapy & 57 & 24 & 5 & 1 & 0 \\
\hline \multicolumn{6}{|l|}{ Probability of transplant [35] } \\
\hline $\mathrm{GO}+$ standard chemotherapy & 29 & 21 & 15 & 10 & 7 \\
\hline Standard chemotherapy & 52 & 25 & 12 & 6 & 3 \\
\hline
\end{tabular}

Data are expressed as percentages

$A M L$ acute myeloid leukemia, $G O$ gemtuzumab ozogamicin

${ }^{a}$ The ALFA-0701 trial reports outcomes through 3 years [35]. As such, outcomes for years 4 and 5 are extrapolated, assuming a best-fit curve based on the observed data for years 1-3 
based on ALFA-0701 [20]. In the absence of a suitable data source for patients treated in the second-line setting, a mean (SD) BSA of $1.83 \mathrm{~m}^{2}(0.198)$ was assumed based on the ALFA-0701 trial [20].

The treatment regimen for GO was $3 \mathrm{mg} / \mathrm{m}^{2}$ (up to one $4.5 \mathrm{mg}$ vial) on days 1, 4, and 7 [12]. Dosages for the comparator regimens were as follows: $\mathrm{HiDAC}=$ high-dose cytarabine $2000 \mathrm{mg} / \mathrm{m}^{2}$, daunorubicin $45 \mathrm{mg} / \mathrm{m}^{2}$, idarubicin $8 \mathrm{mg} / \mathrm{m}^{2}$, and mitoxantrone $8 \mathrm{mg} / \mathrm{m}^{2}$; FLAG-IDA = fludarabine $30 \mathrm{mg} / \mathrm{m}^{2}$, cytarabine $1500 \mathrm{mg} / \mathrm{m}^{2}$, idarubicin $10 \mathrm{mg} /$ $\mathrm{m}^{2}$, and G-CSF $263 \mathrm{mg} / \mathrm{kg}$; and $\mathrm{MEC}=$ mitoxantrone $8 \mathrm{mg} /$ $\mathrm{m}^{2}$, etoposide $100 \mathrm{mg} / \mathrm{m}^{2}$, and cytarabine $1000 \mathrm{mg} / \mathrm{m}^{2}$. An equal split was assumed among the three comparator regimens.

Again, drug dosing in both treatment settings was determined using a method-of-moments analysis capturing the variation in BSA around the mean and its impact on vial use (Online Resource 3). A scenario analysis considering drug dosage based on mean weight and BSA was included. The unit prices of the treatments were sourced from Red Book 2017 [31] and were used to calculate drug acquisition costs.

The model examined different estimated uptake rates (base-case estimate in Table 2); scenario analyses reflected a $20 \%$ higher and a $20 \%$ lower treatment uptake for GO and the lowest price per unit across the formulation of each treatment option, along with assuming drug dosing based on mean weight and body surface area.

Due to a paucity of data on AEs and treatment-related outcomes in R/R AML for the comparators, we assumed that AEs (frequency and type) and outcomes (response rates, length of hospital stay, and subsequent treatment) were the same for the GO and comparator arms. Thus, as with the newly diagnosed monotherapy population, we do not present these costs as they do not contribute to the incremental budget impact of GO. Additionally, we assumed the same treatments for the pediatric population as assumed in the adult population due to limited availability of data in the pediatric $\mathrm{R} / \mathrm{R}$ AML population.

\subsection{Scenario Analyses}

To address uncertainty with the model and the accompanying effect on budget impact, we considered the following scenario analyses: (1) varying market uptake scenarios $\pm 20 \%$; (2) drug dosing based on mean weight and body surface area (base-case assumes dosing based on the method of moments); (3) applying an additional cost of survival for incremental survival of GO patients compared with alternative regimens (base-case assumes no difference in survival; applicable only to the combination therapy setting); and (4) assuming only the pharmacy budget impact for the combination therapy setting.

\section{Results}

\subsection{Newly Diagnosed AML}

Approximately 29 patients with newly diagnosed AML were eligible for GO in combination with standard chemotherapy each year in the modeled health plan. Base-case results indicated that the addition of GO in the combination setting reduced the overall budget of a 1-million-member health plan (Fig. 2a). Specifically, the estimated net cost (US\$) savings ranged from $\$ 72,969$ ( $\$ 0.006$ PMPM) in year 1 to $\$ 745,426$ (\$0.062 PMPM) in year 5. The use of GO was expected to increase drug costs and healthcare costs due to AEs and overall survival. However, patients in this setting were expected to experience fewer relapses and transplants, resulting in substantial cost offsets in each year. Scenario analyses demonstrated that the cost savings for all years were robust to parameter uncertainty, with the exception of the scenario considering only the pharmacy budget impact (Table 3).

Approximately nine patients with newly diagnosed AML were eligible for single-agent GO each year in the modeled health plan. Base-case results indicated that the introduction of GO in this setting resulted in increased net costs (US\$) in all years, although the PMPM net costs each year were negligible $(<\$ 0.003)$. The estimated net cost (US\$) ranged from $\$ 4118$ in year 1 to $\$ 31,885$ in year 5 (Fig. $2 b$ ). The increase was expected due to the greater cost of GO compared with the alternative treatment regimens, as we assumed no differences in safety and efficacy due to the lack of available data for comparative effectiveness. Scenario analyses indicated that the budget impact was not overly sensitive to the selected input assumptions (Table 3).

\subsection{Relapsed/Refractory AML}

In the modeled health plan, approximately 17 adult patients and 1 pediatric patient were eligible for single-agent $\mathrm{GO}$ for $\mathrm{R} / \mathrm{R}$ AML each year. Base-case results indicated that the introduction of GO for R/R AML resulted in increased costs in all years due to the greater cost of GO compared with the alternative treatments (Fig. 3). The net budget impact to the health plan ranged from $\$ 17,326$ in year 1 to $\$ 46,163$ in year 5 . However, the net PMPM cost was relatively low in each year $(<\$ 0.004)$ due to the low incidence of AML in the population.

Scenario analyses indicated the budget impact was not overly sensitive to the selected input assumptions (Table 3). No scenario indicated that the introduction of GO would be cost saving. 


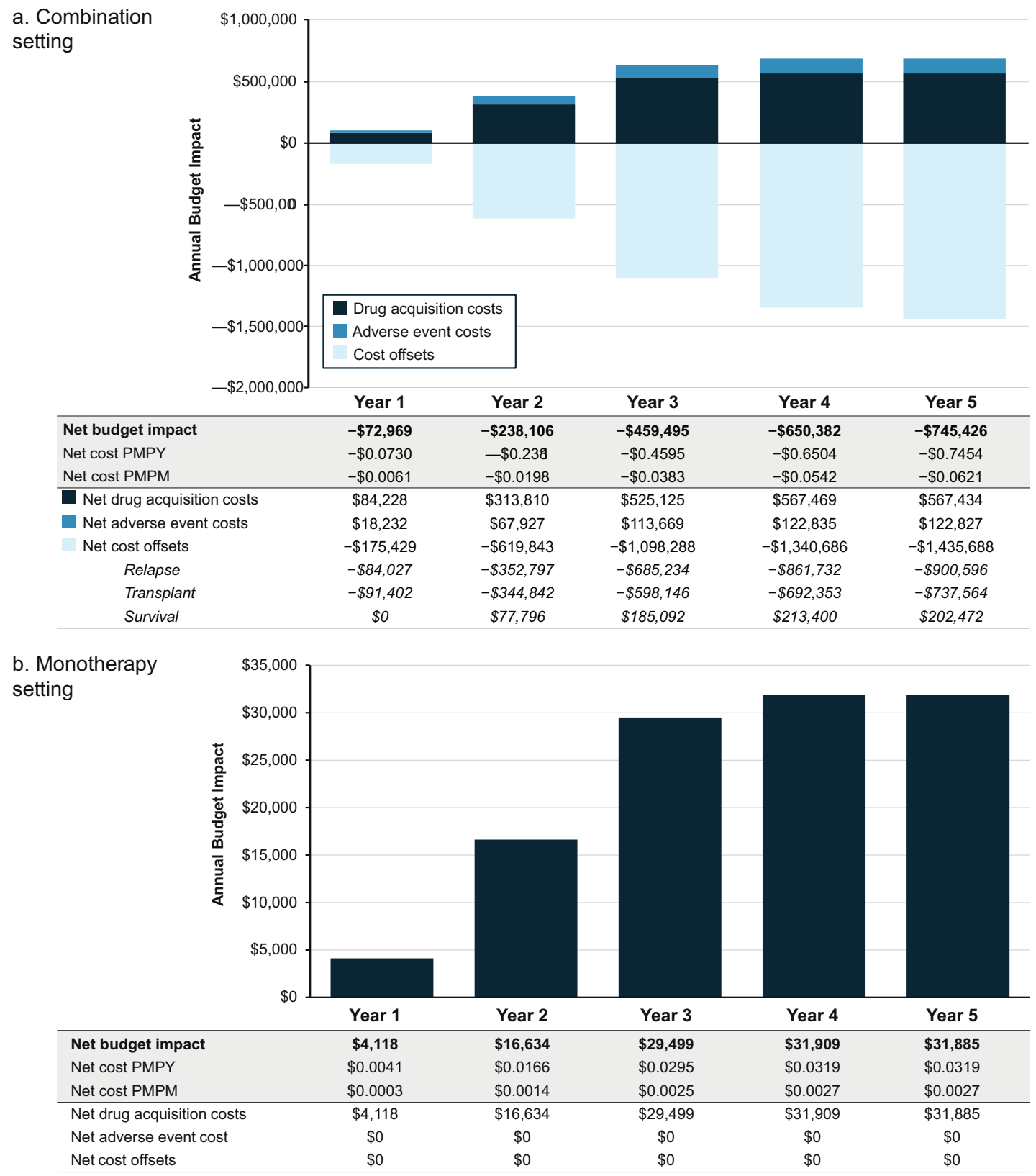

Fig. 2 Net annual budget impact of adding GO for newly diagnosed AML $\mathbf{a}$ in combination with standard chemotherapy and $\mathbf{b}$ as monotherapy. $A M L$ acute myeloid leukemia, $G O$ gemtuzumab ozogamicin, $P M P M$ per member per month, $P M P Y$ per member per year

\section{Discussion}

AML is associated with a poor prognosis, as evidenced by a low longer-term survival rate and high relapse rate following standard induction therapy $[1,5]$. Treatment is particularly challenging in patients with R/R AML, given the lack of highly efficacious therapeutics, and in older patients, due to an increased risk of toxicity from intensive treatment. GO was approved in 2017 for the treatment of newly diagnosed
CD33+ AML in combination with standard chemotherapy or as monotherapy, and for the treatment of R/R CD33+ AML as monotherapy [12]. This analysis is the first to evaluate the impact of the introduction of GO on the budget of a US health plan.

For newly diagnosed AML, we examined the budgetary impact of introducing GO in combination with standard chemotherapy and as monotherapy. Our analysis indicated 
Table 3 Scenario analyses

\begin{tabular}{|c|c|c|c|c|c|}
\hline & \multicolumn{5}{|c|}{ Annual budget impact (US\$) } \\
\hline & Year 1 & Year 2 & Year 3 & Year 4 & Year 5 \\
\hline \multicolumn{6}{|c|}{ Newly diagnosed $A M L-$ combination therapy } \\
\hline \multicolumn{6}{|c|}{ Scenario 1: $20 \%$ higher treatment uptake each year } \\
\hline Net budget impact & $-72,969$ & $-285,727$ & $-551,394$ & $-780,459$ & $-894,512$ \\
\hline Net cost PMPM & -0.0061 & -0.0238 & -0.0459 & -0.0650 & -0.0745 \\
\hline \multicolumn{6}{|c|}{ Scenario 2: $20 \%$ lower treatment uptake each year } \\
\hline Net budget impact & $-58,375$ & $-190,484$ & $-367,596$ & $-520,306$ & $-596,341$ \\
\hline Net cost PMPM & -0.0049 & -0.0159 & -0.0306 & -0.0434 & -0.0497 \\
\hline \multicolumn{6}{|c|}{ Scenario 3: Drug dosing based on mean weight and body surface area } \\
\hline Net budget impact & $-54,439$ & $-169,067$ & $-343,967$ & $-525,539$ & $-620,591$ \\
\hline Net cost PMPM & -0.0045 & -0.0141 & -0.0287 & -0.0438 & -0.0517 \\
\hline \multicolumn{6}{|c|}{ Scenario 4: Assuming no difference in overall survival for patients receiving GO } \\
\hline Net budget impact & $-72,969$ & $-315,901$ & $-644,587$ & $-863,782$ & $-947,898$ \\
\hline Net cost PMPM & -0.0061 & -0.0263 & -0.0537 & -0.0720 & -0.0790 \\
\hline \multicolumn{6}{|c|}{ Scenario 5: Assuming pharmacy budget impact only } \\
\hline Net budget impact & 84,228 & 313,810 & 525,125 & 567,469 & 567,434 \\
\hline Net cost PMPM & 0.0070 & 0.0262 & 0.0438 & 0.0473 & 0.0473 \\
\hline \multicolumn{6}{|c|}{ Newly diagnosed $A M L-$ monotherapy } \\
\hline \multicolumn{6}{|c|}{ Scenario 1: $20 \%$ higher treatment uptake each year } \\
\hline Net budget impact & 4942 & 19,961 & 35,399 & 38,291 & 38,262 \\
\hline Net cost PMPM & 0.0004 & 0.0017 & 0.0029 & 0.0032 & 0.0032 \\
\hline \multicolumn{6}{|c|}{ Scenario 2: $20 \%$ lower treatment uptake each year } \\
\hline Net budget impact & 3295 & 13,307 & 23,599 & 25,527 & 25,508 \\
\hline Net cost PMPM & 0.0003 & 0.0011 & 0.0020 & 0.0021 & 0.0021 \\
\hline \multicolumn{6}{|c|}{ Scenario 3: Drug dosing based on mean weight and body surface area } \\
\hline Net budget impact & 4118 & 16,634 & 29,499 & 31,909 & 31,885 \\
\hline Net cost PMPM & 0.0003 & 0.0014 & 0.0025 & 0.0027 & 0.0027 \\
\hline \multicolumn{6}{|l|}{$R / R A M L$} \\
\hline \multicolumn{6}{|c|}{ Scenario 1: $20 \%$ higher treatment uptake each year } \\
\hline Net budget impact & 20,791 & 40,086 & 54,259 & 55,258 & 55,395 \\
\hline Net cost PMPM & 0.0017 & 0.0033 & 0.0045 & 0.0046 & 0.0046 \\
\hline \multicolumn{6}{|c|}{ Scenario 2: $20 \%$ lower treatment uptake each year } \\
\hline Net budget impact & 13,860 & 26,724 & 36,172 & 36,839 & 36,930 \\
\hline Net cost PMPM & 0.0012 & 0.0022 & 0.0030 & 0.0031 & 0.0031 \\
\hline \multicolumn{6}{|c|}{ Scenario 3: Lowest price per unit } \\
\hline Net budget impact & 17,763 & 34,239 & 46,327 & 47,171 & 47,288 \\
\hline Net cost PMPM & 0.0015 & 0.0029 & 0.0039 & 0.0039 & 0.0039 \\
\hline \multicolumn{6}{|c|}{ Scenario 4: Drug dosing based on mean weight and body surface area } \\
\hline Net budget impact & 20,601 & 39,653 & 53,547 & 54,458 & 54,594 \\
\hline Net cost PMPM & 0.0017 & 0.0033 & 0.0045 & 0.0045 & 0.0045 \\
\hline
\end{tabular}

$A M L$ acute myeloid leukemia, $G O$ gemtuzumab ozogamicin, $P M P M$ per member per month, $R / R$ relapsed/ refractory

that the addition of GO in these settings is associated with minimal impact to the budget of a US health plan. In the combination therapy setting, the addition of GO was expected to be cost saving due to fewer relapses incurred and fewer transplants, whereas in the monotherapy setting, net PMPM costs were low $(<\$ 0.003)$ each year over a 5-year period. Scenario analyses also demonstrated cost savings in the combination therapy setting and low net PMPM costs $(<\$ 0.004)$ each year in the monotherapy setting. It is important to note that the patient population and associated outcomes in the combination therapy model were based on the ALFA-0701 population, in which $67 \%$ of patients were 


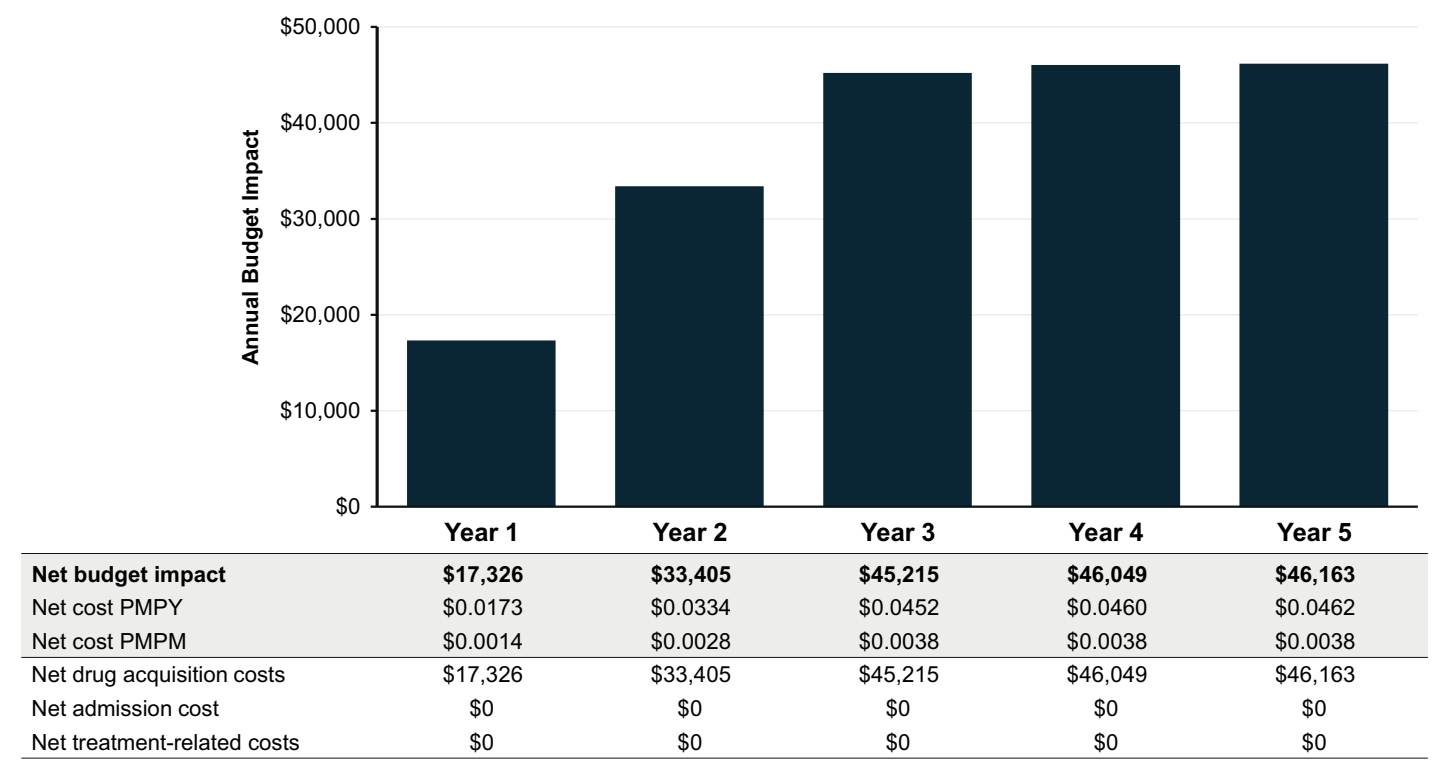

Fig. 3 Net annual budget impact of adding GO for R/R AML. $A M L$ acute myeloid leukemia, $G O$ gemtuzumab ozogamicin, $P M P M$ per member per month, $P M P Y$ per member per year, $R / R$ relapsed/refractory

$\geq 60$ years of age. Therefore, outcome estimates were based on a population of both younger and older patients.

Additionally, we examined the impact of introducing GO as monotherapy for adults and pediatric patients with $\mathrm{R} / \mathrm{R}$ AML. Under all scenarios, the introduction of GO as second-line treatment of AML resulted in a minimal additional cost to the budget of a US health plan. Cost increases were solely due to the cost of GO being greater than that of the comparator treatments, and the overall budget impact was small $(<\$ 0.004$ PMPM) each year given the rarity of the disease.

From a clinical perspective, patients treated with GO in addition to standard chemotherapy versus standard chemotherapy in the ALFA-0701 trial had significantly longer event-free survival and no differences in the mean number of hospitalizations and the length of hospital stay [35, 40]. Therefore, the addition of GO may provide considerable clinical value at minimal cost to a health plan and carries a hospitalization burden comparable with standard induction therapy. In the monotherapy setting, the cost to a health plan is expected to be negligible given the small patient population, but the addition of GO would provide an alternative treatment option for this difficult-to-treat population.

Other agents have been introduced in the last 2-3 years for the treatment of AML. These include CPX-351, a dualdrug liposomal encapsulation of daunorubicin and cytarabine, which was approved for treatment-related AML and AML with myelodysplasia-related changes [41]; and the isocitrate dehydrogenase-2 (IDH2) inhibitor enasidenib, which was approved for the treatment of R/R AML with an
IDH2 mutation [13]. Budget impact analyses of these agents demonstrated that the addition of each of these drugs to a US health plan would also result in a small budget increase, with PMPM estimates $<\$ 0.02$ for CPX-351 over 5 years and $<\$ 0.02$ for enasidenib over 3 years $[42,43]$. These results are similar to the budget impact we estimated GO would have on a US health plan, although we predicted cost savings in later years in the combination therapy setting. Overall, newer treatments for AML appear to be associated with some increase in cost to a US health plan, but the impact on the budget is expected to be negligible.

The current findings should be considered in light of the limitations of the analysis, which were primarily related to a lack of robust clinical trial data on which to base several of our inputs. We addressed these data gaps in the newly diagnosed model by assuming no differences in rates of AEs, transplant, or relapse between the GO and comparator arms in the monotherapy setting. Although it is unclear which direction these assumptions drive results, any outcomerelated cost differences would have a very small effect on the overall budget impact, given a low uptake estimate for GO in this setting. In the R/R AML model, we assumed that the rates of AEs, number of courses of treatment, and treatment-related outcomes for adults and pediatric patients with R/R AML were equal between the GO and comparator arms. Therefore, the cost of GO was the only difference between the two arms in this model, an assumption considered conservative. 


\section{Conclusions}

Our analysis suggests that adding GO to a US health plan would result in minimal budget impact. Increased costs were largely offset by reductions in medical costs related to fewer transplants and relapses for newly diagnosed AML. Furthermore, the low incremental drug costs and small patient population suggest that GO may provide an alternative option for patients with R/R AML at minimal incremental cost for health plans.

Acknowledgements Medical writing support was provided by Emily Balevich, PhD, of Engage Scientific Solutions, and was funded by Pfizer.

\section{Declarations}

Funding This study was sponsored by Pfizer.

Conflict of interest Carla Mamolo, Verna Welch, and Joseph C. Cappelleri are employees of and own stock in Pfizer. James Brockbank, Chris Knight, and Michele Wilson are employees of RTI-HS, and Matthew Cawson was an employee of RTI-HS at the time of manuscript development; RTI-HS received consulting fees from Pfizer for work related to this manuscript. Roland B. Walter has no conflicts of interest to declare.

Availability of data and material Data are from publicly available sources.

Code availability The code for the model is not publicly available.

Consent to participate Not Applicable.

consent for publication Not Applicable.

Author contributions $\mathrm{CM}, \mathrm{VW}, \mathrm{JCC}, \mathrm{JB}, \mathrm{CK}$, and $\mathrm{MW}$ contributed to the study design/conception. CM, JCC, JB, CK, and MW analyzed the data. CM, VW, RBW, JCC, MC, CK, and MW contributed to data interpretation. All authors drafted or critically revised the manuscript and provided approval of the final version.

Open Access This article is licensed under a Creative Commons Attribution-NonCommercial 4.0 International License, which permits any non-commercial use, sharing, adaptation, distribution and reproduction in any medium or format, as long as you give appropriate credit to the original author(s) and the source, provide a link to the Creative Commons licence, and indicate if changes were made. The images or other third party material in this article are included in the article's Creative Commons licence, unless indicated otherwise in a credit line to the material. If material is not included in the article's Creative Commons licence and your intended use is not permitted by statutory regulation or exceeds the permitted use, you will need to obtain permission directly from the copyright holder. To view a copy of this licence, visit http://creativecommons.org/licenses/by-nc/4.0/.

\section{References}

1. National Cancer Institute (NIH). SEER Cancer Facts: acute myeloid leukemia (AML). (Last update: 2019). https://seer. cancer.gov/statfacts/html/amyl.html. Accessed 17 May 2020.

2. Dombret H, Gardin C. An update of current treatments for adult acute myeloid leukemia. Blood. 2016;127:53-61.

3. Dohner H, Estey E, Grimwade D, et al. Diagnosis and management of AML in adults: 2017 ELN recommendations from an international expert panel. Blood. 2017;129:424-47.

4. Dohner H, Weisdorf DJ, Bloomfield CD. Acute myeloid leukemia. N Engl J Med. 2015;373:1136-52.

5. Dohner H, Estey EH, Amadori S, et al. Diagnosis and management of acute myeloid leukemia in adults: recommendations from an international expert panel, on behalf of the European LeukemiaNet. Blood. 2010;115:453-74.

6. Craddock C, Tauro S, Moss P, Grimwade D. Biology and management of relapsed acute myeloid leukaemia. Br J Haematol. 2005;129:18-34.

7. National Comprehensive Cancer Network (NCCN). NCCN clinical practice guidelines in oncology: acute myeloid leukemia. Version 1.2021. NCCN; 2020. https://www.nccn.org/profession als/physician_gls/pdf/aml.pdf. Accessed 12 Nov 2020.

8. Tallman MS, Gilliland DG, Rowe JM. Drug therapy for acute myeloid leukemia. Blood. 2005;106:1154-63.

9. Watts J, Nimer S. Recent advances in the understanding and treatment of acute myeloid leukemia. F1000Res. 2018;7:F1000 Faculty Rev-1196.

10. Pemmaraju N, Kantarjian H, Garcia-Manero G, et al. Improving outcomes for patients with acute myeloid leukemia in first relapse: a single center experience. Am J Hematol. 2015;90:27-30.

11. Talati C, Sweet K. Recently approved therapies in acute myeloid leukemia: a complex treatment landscape. Leuk Res. 2018;73:58-66.

12. Pfizer Inc. Mylotarg (gemtuzumab ozogamicin) prescribing information. 2017 (last update: Sep 2017). https://www.accessdata.fda. gov/drugsatfda_docs/label/2017/761060lbl.pdf. Accessed 14 Apr 2020.

13. Celgene Corporation. Idhifa (enasidenib) prescribing information. 2017 (last update: Aug 2017). https://www.accessdata.fda.gov/ drugsatfda_docs/label/2017/209606s000lbl.pdf. Accessed 14 Apr 2020.

14. Novartis. Rydapt (midostaurin) prescribing information. 2017 (last update: Apr 2017). https://www.accessdata.fda.gov/drugs atfda_docs/label/2017/207997s000lbl.pdf. Accessed 14 Apr 2020.

15. Jazz Pharmaceuticals. Vyxeos (daunorubicin and cytarabine) prescribing information. 2017 (last update: Aug 2017). https://www. accessdata.fda.gov/drugsatfda_docs/label/2017/209401s000lbl. pdf. Accessed 14 Apr 2020.

16. Agios Pharmaceuticals. Tibsovo (ivosidenib) prescribing information. 2018 (last update: May 2019). https://www.accessdata.fda. gov/drugsatfda_docs/label/2019/211192s001lbl.pdf. Accessed 14 Apr 2020.

17. AbbVie Inc. Venclexta (venetoclax) prescribing information. 2019 (last update: Apr 2016). https://www.accessdata.fda.gov/drugs atfda_docs/label/2016/208573s000lbl.pdf. Accessed 10 Apr 2020.

18. Pfizer Inc. Daurismo (glasdegib) prescribing information. 2018 (last update: Nov 2018). https://www.accessdata.fda.gov/drugs atfda_docs/label/2018/210656s000lbl.pdf. Accessed 14 Apr 2020.

19. Ehninger A, Kramer M, Rollig C, et al. Distribution and levels of cell surface expression of CD33 and CD123 in acute myeloid leukemia. Blood Cancer J. 2014;4:e218. 
20. Castaigne S, Pautas C, Terre C, et al. Effect of gemtuzumab ozogamicin on survival of adult patients with de-novo acute myeloid leukaemia (ALFA-0701): a randomised, open-label, phase 3 study. Lancet. 2012;379:1508-16.

21. Burnett AK, Hills RK, Milligan D, et al. Identification of patients with acute myeloblastic leukemia who benefit from the addition of gemtuzumab ozogamicin: results of the MRC AML15 trial. J Clin Oncol. 2011;29:369-77.

22. Burnett AK, Russell NH, Hills RK, et al. Addition of gemtuzumab ozogamicin to induction chemotherapy improves survival in older patients with acute myeloid leukemia. J Clin Oncol. 2012;30:3924-31.

23. Amadori S, Suciu S, Selleslag D, et al. Gemtuzumab ozogamicin versus best supportive care in older patients with newly diagnosed acute myeloid leukemia unsuitable for intensive chemotherapy: results of the randomized phase III EORTC-GIMEMA AML-19 trial. J Clin Oncol. 2016;34:972-9.

24. Taksin AL, Legrand O, Raffoux E, et al. High efficacy and safety profile of fractionated doses of Mylotarg as induction therapy in patients with relapsed acute myeloblastic leukemia: a prospective study of the alfa group. Leukemia. 2007;21:66-71.

25. Wiese M, Daver N. Unmet clinical needs and economic burden of disease in the treatment landscape of acute myeloid leukemia. Am J Manag Care. 2018;24:S347-55.

26. Medeiros BC, Pandya BJ, Chen C-C, et al. Economic burden of treatment episodes in acute myeloid leukemia (AML) patients in the US: a retrospective analysis of a commercial payer database. Blood. 2017;130:4694.

27. Vaughn JE, Shankaran V, Walter RB. Trends in clinical benefits and costs of novel therapeutics in AML: at what price does progress come? Curr Hematol Malig Rep. 2019;14:171-8.

28. Sullivan SD, Mauskopf JA, Augustovski F, et al. Budget impact analysis-principles of good practice: report of the ISPOR 2012 Budget Impact Analysis Good Practice II Task Force. Value Health. 2014;17:5-14

29. Pearson K. Contributions to the mathematical theory of evolution. II. Skew variation in homogeneous material. Philos Trans R Soc Lond Ser A. 1895;186:343-414.

30. Hatswell AJ, Porter J, Lee D, et al. The cost of costing treatments incorrectly: errors in the application of drug prices in economic evaluation due to failing to account for the distribution of patient weight. Value Health. 2016;19:1055-8.

31. Truven Health. Red Book ${ }^{\circledR}$ Online. 2017. https://www.ibm.com/ us-en/marketplace/micromedex-red-book. Accessed 1 Nov 2017.

32. Ghate SR, Li Z, Tang J, Nakasato AR. Economic burden of adverse events associated with immunotherapy and targeted therapy for metastatic melanoma in the elderly. Am Health Drug Benefits. 2018;11:334-43.
33. Mauskopf J, Chirila C, Graham J, et al. Comparative costeffectiveness analysis of voriconazole and fluconazole for prevention of invasive fungal infection in patients receiving allogeneic hematopoietic cell transplants. Am J Health Syst Pharm. 2013;70:1518-27.

34. Tai E, Guy GP, Dunbar A, Richardson LC. Cost of cancer-related neutropenia or fever hospitalizations, United States, 2012. J Oncol Pract. 2017;13:e552-61.

35. Lambert J, Pautas C, Terre C, et al. Gemtuzumab ozogamicin for de novo acute myeloid leukemia: final efficacy and safety updates from the open-label, phase III ALFA-0701 trial. Haematologica. 2019;104:113-9.

36. Broder MS, Quock TP, Chang E, et al. The cost of hematopoietic stem-cell transplantation in the United States. Am Health Drug Benefits. 2017;10:366-74.

37. Pandya BJ, Chen CC, Medeiros BC, et al. Economic and clinical burden of relapsed and/or refractory active treatment episodes in patients with acute myeloid leukemia (AML) in the USA: a retrospective analysis of a commercial payer database. Adv Ther. 2019;36:1922-35.

38. Bell JA, Galaznik A, Farrelly E, et al. Economic burden of elderly patients with acute myeloid leukemia treated in routine clinical care in the United States. Leuk Res. 2018;71:27-33.

39. Walter RB, Othus M, Burnett AK, et al. Resistance prediction in AML: analysis of 4601 patients from MRC/NCRI, HOVON/ SAKK, SWOG and MD Anderson Cancer Center. Leukemia. 2015;29:312-20.

40. Sikirica S, Russell-Smith TA, Welch VL, et al. Gemtuzumab ozogamicin plus standard chemotherapy carries a comparable burden of hospitalization compared with standard chemotherapy alone in acute myeloid leukemia. Value Health. 2020;23:S26.

41. Krauss AC, Gao X, Li L, et al. FDA approval summary: (daunorubicin and cytarabine) liposome for injection for the treatment of adults with high-risk acute myeloid leukemia. Clin Cancer Res. 2019;25:2685-90.

42. Graham C, McGuire M, Knox H, Ung B. Budget impact analysis of enasidenib treatment in patients with relapsed or refractory acute myeloid leukemia with an isocitrate dehydrogenase- 2 mutation. J Manag Care Pharm. 2018;24:S31.

43. Jensen IS, Wu E, Sacks N, et al. Budget impact analysis of CPX-351 in the treatment of patients with treatment-related acute myeloid leukemia (tAML) or AML with myelodysplasiarelated changes (MRC) from a US payer perspective. Blood. 2017;130:5615. 